\title{
Expert face coding: Configural and component coding of own-race and other-race faces
}

\author{
GILLIAN RHODES \\ University of Western Australia, Crawley, Western Australia, Australia \\ WILLIAM G. HAYWARD \\ University of Hong Kong, Honk Kong, China \\ and \\ CHRISTOPHER WINKLER \\ University of Western Australia, Crawley, Western Australia, Australia
}

\begin{abstract}
Configural and holistic coding are hallmarks of face perception. Although recent studies have shown that own-race faces are coded more holistically than other-race faces, the evidence for better configural coding of own-race faces is equivocal. We directly measured configural and component coding of own- and other-race male faces in Caucasian and Chinese participants. We manipulated individual features (components) or their spatial relations (configurations) using a novel morphing method to vary difficulty parametrically and tested sensitivity to these changes in a sequential matching task. Both configural and component coding were better for upright own-race than for upright other-race faces. Inversion impaired detection of configural changes more than it did detection of component changes, but also impaired performance more for easier discriminations, independent of type of change. These results challenge explanations of face expertise that rely solely on configural and holistic processing, and also call into question the widespread interpretation of large inversion decrements as diagnostic of configural coding.
\end{abstract}

We are all face experts, with a remarkable ability to distinguish thousands of faces, despite their similarity as visual patterns. This expertise results from years of experience in individuating faces (Carey, 1992) and draws on face-selective ${ }^{1}$ brain regions (Haxby, Hoffman, \& Gobbini, 2000; Kanwisher, 2000) and computational mechanisms, such as configural and holistic coding (Peterson $\&$ Rhodes, 2003). Configural coding refers to coding of spatial relations between components (parts or features). ${ }^{2}$ Holistic coding refers to the coding of perceptual wholes, with little decomposition into parts, and is inferred from better recognition of face parts in the whole face than in isolation (see, e.g., Tanaka \& Farah, 1993).

Holistic coding has been taken as a hallmark of face processing, because the wholes advantage is greater for faces than for other objects, including scrambled and inverted faces (Farah, Wilson, Drain, \& Tanaka, 1998; Tanaka \& Farah, 1993, 2003). Configural coding has

This work was supported by the Australian Research Council and by the Research Grants Council of the Hong Kong Special Administrative Region (Project No. HKU 4260/03H). We thank Keung-Tat Lee and Hoi-Yan Lam for assistance with stimulus construction and data collection, Louise Ewing for assistance with figures and data processing, and Daphne Maurer and Linda Jeffery for comments on an earlier version of the manuscript. Correspondence concerning this article should be addressed to G. Rhodes, School of Psychology, University of Western Australia, 35 Stirling Highway, Crawley, WA 6009, Australia (e-mail: gill@psy.uwa.edu.au). been taken as a hallmark of face processing because inversion, which disrupts configural processing, disrupts recognition of faces more than it does recognition of most other objects (for reviews, see Bartlett, Searcy, \& Abdi, 2003; Murray, Rhodes, \& Schuchinsky, 2003; Rossion \& Gauthier, 2002).

Although we are all face experts, we are more expert with some classes of faces than with others. For many people, expertise is greater for own-race faces than for other-race faces, resulting in poorer recognition memory (Bothwell, Brigham, \& Malpass, 1989; Brigham, Maass, Snyder, \& Spaulding, 1982; Meissner \& Brigham, 2001; Platz \& Hosch, 1988), poorer perceptual discrimination (Byatt \& Rhodes, 2004; Murray et al., 2003; Walker \& Tanaka, 2003), poorer change detection (Humphreys, Hodsoll, \& Campbell, 2005), and less accurate judgments of age (Dehon \& Brédart, 2001) and sex (O'Toole, Peterson, \& Deffenbacher, 1996) for other-race faces. These deficits probably reflect limited experience in individuating otherrace faces (Chiroro \& Valentine, 1995; Furl, Phillips, \& O'Toole, 2002; Goldstone, 2003; Meissner \& Brigham, 2001), which results in other-race faces' being more tightly clustered than own-race faces in face space (Byatt \& Rhodes, 2004), and possibly less effective activation of neural face coding mechanisms by other-race faces (Caldara et al., 2003; Golby, Gabrieli, Chiao, \& Eberhardt, 2001).

What is the computational basis of these own-race processing advantages? Recent reports suggest that Caucasians process Asian faces less holistically than they do 
Caucasian faces (Michel, Caldara, \& Rossion, 2006; Tanaka, Kiefer, \& Bukach, 2004). Asian participants processed Caucasian faces as holistically as Asian faces, perhaps because the Asian participants lived in Western countries and had extensive experience with Caucasian faces. It remains to be seen whether Asian participants in Asian countries have an own-race advantage in holistic coding. Interestingly, the Asian participants still showed an own-race advantage in recognition memory, despite normal holistic processing of other-race faces, suggesting that a holistic processing difference is not the only factor in own-race face expertise (Michel et al., 2006).

Configural coding mechanisms may also be differentially engaged by own- and other-race faces, although here the evidence is weaker. Two studies have inferred greater configural coding of own-race faces from larger inversion decrements for own-race faces (Rhodes, Tan, Brake, \& Taylor, 1989; Sangrigoli \& de Schonen, 2004; but see Valentine \& Bruce, 1986). This inference rests on the fact that inversion selectively disrupts configural information (Diamond \& Carey, 1986; Rhodes et al., 1989; Rossion \& Gauthier, 2002). However, inversion also impairs holistic coding (Farah, Tanaka, \& Drain, 1995; Tanaka \& Farah, 1993) and component coding, albeit to a lesser degree (see, e.g., Mondloch, Le Grand, \& Maurer, 2002; for a review, see Bartlett et al., 2003). Therefore, inversion decrements may reflect some unknown combination of impaired configural, component, and holistic coding.

In a more direct test of configural coding in own- and other-race faces, Murray et al. (2003) created bizarre faces by inverting eyes and mouths in Caucasian and Asian faces (creating "Thatcherized" faces), and found greater sensitivity to these configural changes in own-race than in other-race faces. However, these results may not generalize to natural variations in face configurations. Furthermore, the transformations also affected the appearance of components, making it difficult to be sure that the results reflected differences in configural coding. Finally, only Caucasians were tested, making it difficult to rule out the possibility that the configural changes were more salient in Caucasian faces than in Asian faces (e.g., if Caucasian eyes or mouths are less horizontally symmetric).

These studies have focused on configural and holistic coding because these are considered to be the hallmarks of face expertise. However, component coding also contributes to face recognition (e.g., Bartlett et al., 2003; Cabeza \& Kato, 2000; McKone \& Peh, 2006) and could be better for own-race faces. Murray et al. (2003) also examined race effects in component coding. In addition to the configural manipulations described earlier, they created bizarre faces by altering features and found no difference in the sensitivity to these changes in own- and other-race faces. However, the changes were extreme (blackened teeth, whitened eyes), and the results may not generalize to more normal faces.

Here we directly assessed adults' sensitivity to configural and component changes in own-race and other-race faces. Unlike in previous studies, we did not infer config- ural coding differences from differences in the size of inversion decrements, and we did not use extreme changes. Instead, we directly manipulated configural and component information in grayscale images of Caucasian and Chinese male faces. We also used a novel method to vary the difficulty of the configural and component discriminations parametrically, in case any own-race advantages are restricted to difficult discriminations. We tested both Caucasian participants living in Western Australia (a Caucasian majority population) and Chinese participants living in Hong Kong (a Chinese majority population), so that race effects could not be attributed to differences in the face sets.

Configural changes were made by simultaneously altering (reducing or increasing) the spacing between the eyes, nose, and mouth. Spacing changes are typically used to manipulate configural information (for reviews, see Bartlett et al., 2003; Maurer, Le Grand, \& Mondloch, 2001). Many component changes can also affect configural information. For example, changing the size or shape of component features can also change their spatial relations. We made component changes by simultaneously altering eye and lip brightness and nose shape (making the end of the nose more or less bulbous without changing its distance from the eyes and mouth) (cf. Freire, Lee, \& Symons, 2000; Leder \& Bruce, 2000). These component changes have minimal impact on configuration (spacing) and can be used to individuate people (eye and lip color differences appear as brightness differences in grayscale images). For each face, we created a configural continuum with features closely spaced at one end and widely spaced at the other, and a series of morphed images in between. We also created an analogous component continuum for each face. By selecting test pairs at varying degrees of separation from these continua, we could vary discrimination difficulty. On each trial, participants saw a study face, followed by two test faces, and indicated which test face matched the study face. Inverted trials were included as a manipulation check, with larger inversion decrements expected for configural than for component changes.

\section{METHOD}

\section{Participants}

Forty young adult Caucasians ( 14 male, 26 female) were recruited from the University of Western Australia, and 40 young adult Chinese ( 17 male, 23 female) were recruited from the Chinese University of Hong Kong.

\section{Stimuli}

Forty-eight front-facing, grayscale male faces (24 Caucasian, 24 Chinese) with neutral expressions were used. The Caucasian and Chinese faces were drawn from the same populations as were the Caucasian and Chinese participants, respectively, to ensure maximal expertise with the own-race faces. The images were standardized with horizontally aligned pupils 80 pixels apart. Blemishes and jewelry were digitally removed. The final images were autocontrasted (in Photoshop), pasted onto a $420 \times 320$ pixel (72 ppi) canvas, and surrounded by an oval mask that hid most of the hair, leaving the inner hairline and face outline visible.

We created a configural continuum for each face using Gryphon Morph 2.5, with a features-in version at one end ( $0 \%)$ and a features- 
out version at the other end $(100 \%)$. The features-in version had the eyes moved in ( 8 pixels) and down ( 8 pixels), and the mouth moved up ( 8 pixels). The features-out version had the eyes moved out ( 8 pixels) and up ( 8 pixels), and the mouth moved down (8 pixels). Morphs were created at 5\% steps spanning the features-in and features-out endpoints, by blending the end images in various proportions. For example, the $50 \%$ morph was a $50 / 50$ blend of the two endpoints and resembled the original face, the $20 \%$ morph was an $80 / 20$ blend of the features-in and features-out images, and so forth. From each continuum, we selected test pairs that differed by $10 \%(45 \%$ and $55 \%$ morphs), $20 \%$ ( $40 \%$ and $60 \%$ morphs), $30 \%$ (35\% and $65 \%$ morphs), and $40 \%$ (30\% and $70 \%$ morphs) (see Figure 1$)$.

Analogous component continua were made for each face. One endpoint $(0 \%)$ had $50 \%$ lighter eyebrows and lips, and a less bulbous nose $(-80 \%$ spherize in Photoshop), than did the original face; the other endpoint (100\%) had 50\% darker eyebrows and lips, and a more bulbous nose $(+80 \%$ spherize). We selected test pairs from each continuum that differed by $10 \%, 20 \%, 30 \%$, and $40 \%$ steps (Figure 1). Note that morph level differences cannot be compared directly for configural and component changes, because the endpoints of these two kinds of continua may not be equally discriminable, but that in each case the discriminations become more difficult as the morph level differences decrease.

The morphs used did not look unusual. There were 16 kinds of face pairs (upright/inverted $\times$ configural/component $\times 10 \%$ / $20 \% / 30 \% / 40 \%$ morph weighting difference) for each of the 48 original faces (24 Caucasian, 24 Chinese), making a total of 768 pairs. The original 48 faces were divided into two sets (A and B) balanced for race of face, resulting in two sets of 384 pairs balanced for orientation, type of change, race of face, and morph weighting difference.

\section{Procedure}

A delayed matching-to-sample procedure was used. On each trial, a study face appeared for $3 \mathrm{sec}$, immediately followed by a pair of test faces. One test face was the study face, and the other was a ver- sion of the study face that differed on either the configural or the component dimension. Using the keyboard, the participant indicated which test face matched the study face. The test faces remained on the screen until the participant responded. All of the faces within a trial were either upright or inverted (orientation) and either Caucasian or Chinese (race of face), all differed on configural or component information (type of change), and all differed by a $10 \%, 20 \%$, $30 \%$, or $40 \%$ step on the relevant continuum (morph difference).

Each participant completed 8 practice trials followed by 384 test trials, balanced for orientation, type of change, race of face, morph difference, which test face was seen at study, and position of target (left/right). For half of the participants, the $10 \%$ and $20 \%$ morph pairs were taken from Face Set $A$ and the $30 \%$ and $40 \%$ morph pairs were taken from Face Set B, and for the other half of the participants, the reverse was true. Trials were presented in random order, in three blocks, with short breaks between blocks. The experiment took approximately $40 \mathrm{~min}$ and was run using SuperLab v1.75 on Macintosh computers with 17 -in. monitors at $1,024 \times 768$ resolution. Faces subtended a viewing angle of approximately $5.4^{\circ}$ in width and $6.8^{\circ}$ in height. Test faces were separated by approximately $3.8^{\circ}$ (between inner edges).

\section{RESULTS}

To examine race expertise effects, we conducted a four-way ANOVA on percent correct scores for upright faces, with participant race as a between-participants factor (Caucasian, Chinese) and face race (own-race, otherrace), change type (configural, component), and morph difference $(10 \%, 20 \%, 30 \%, 40 \%)$ as repeated measures factors (Figure 2). An additional four-way ANOVA was conducted on inversion decrement scores [(upright inverted)/upright $\times 100 \%$ ] to examine how inversion affected face coding. ${ }^{3}$

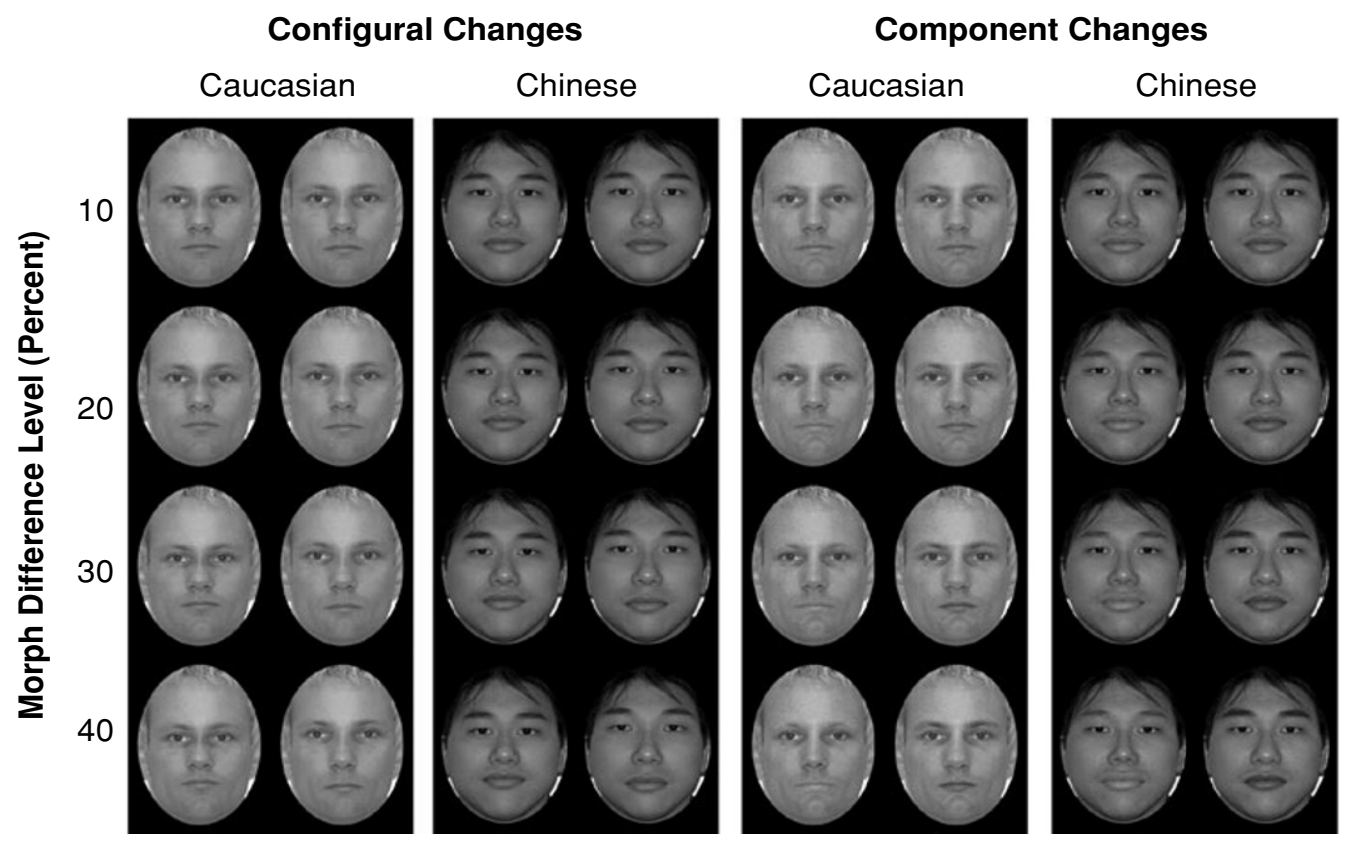

Figure 1. Examples of Caucasian and Chinese face pairs that differ along the configural or component continua by $10 \%, 20 \%, 30 \%$, and $40 \%$ morph weighting. 


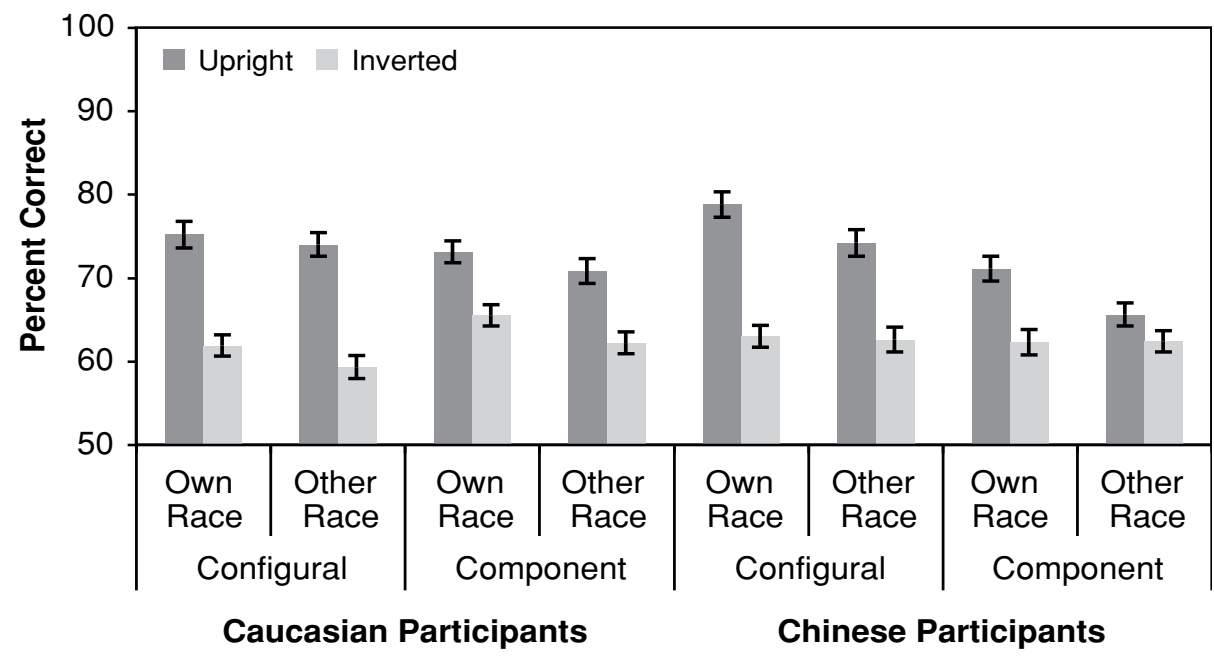

Figure 2. Percent correct for Caucasian and Chinese participants as a function of change type, face race, and orientation. Standard error bars are shown.

\section{Accuracy on Upright Faces}

Accuracy was significantly higher for own-race $(M=$ 74.6, $S E=0.7)$ than for other-race $(M=71.1, S E=0.8)$ faces $[F(1,78)=27.05, p<.0001]$. This own-race advantage was larger for Chinese (own-race, $M=75.0, S E=$ 1.1; other-race, $M=69.9, S E=1.1)$ than for Caucasian (own-race, $M=74.1, S E=1.0$; other-race, $M=72.4$, $S E=1.0)$ participants $[F(1,78)=6.47, p<.02]$ but was significant for both $(t \mathrm{~s}>1.82, p \mathrm{~s}<.05$, one-tailed). The own-race advantage did not interact with change type $[F(1,78)=0.44, p=.51]$ and was significant for both change types $(t \mathrm{~s}>2.73, p \mathrm{~s}<.01)($ Figure 3$)$. There was no interaction between face race and morph difference $[F(3,234)=1.44, p=.23]$, indicating that the own-race advantage was unaffected by task difficulty over the range examined here.

Not surprisingly, performance improved as the morph difference increased $[F(3,234)=377.26, p<.0001]$ $(10 \%, M=55.5, S E=0.9 ; 20 \%, M=68.3, S E=0.9$; $30 \%, M=79.1, S E=0.8 ; 40 \%, M=88.5, S E=0.7)$. The relative difficulty of configural and component changes depends entirely on the discriminability of the end points used for the two kinds of continua. Informally, we tried to equate these, but did not succeed, as was indicated by a significant effect of change type $[F(1,78)=$ 17.67, $p<.0001]$. Configural changes were easier $(M=$ $75.5, S E=0.8)$ than component changes $(M=70.1$, $S E=0.7)$, particularly for Chinese participants, with a significant interaction between change type and participant race $[F(1,78)=4.66, p<.04]$. Participant race also interacted with morph difference $[F(3,234)=2.78, p<$ $.05]$, reflecting small differences in the relative difficulty of the $10 \%, 20 \%, 30 \%$, and $40 \%$ pairs, for Caucasian and Chinese participants, which had no theoretical significance. There were no other significant effects. ${ }^{4}$

\section{Inversion Decrement Analysis}

Inversion impaired detection of configural changes $(M=13.6, S E=1.3)$ more than it did component changes $(M=3.5, S E=1.8)[F(1,78)=21.81, p<.0001]$, validating our manipulation of these changes (but see below). Inversion effects were not greater for own-race than for other-race faces, even for configural changes. There was no main effect of face race and no interaction with change type (both $F_{\mathrm{s}}<1$ ). An important, but unexpected, result was that inversion decrements increased as the upright discrimination became easier (Figure 4) $(10 \%, M=$ $-3.7, S E=3.4 ; 20 \%, M=6.4, S E=2.0 ; 30 \%, M=$ 13.2, $S E=1.5 ; 40 \%, M=18.3, S E=1.1)[F(3,234)=$ $17.37, p<.0001]$. This effect did not interact with type of change $(F<1)$. It was not simply a floor effect, because

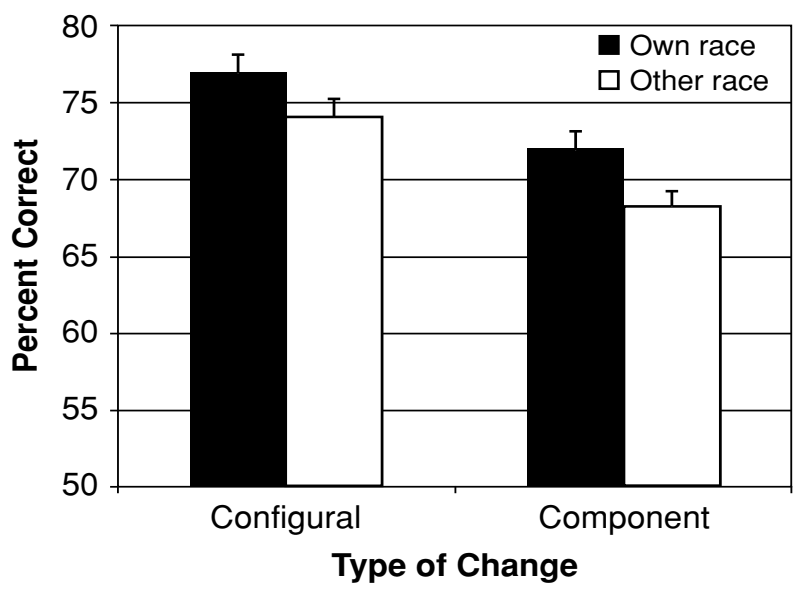

Figure 3. Percent correct for detecting configural and component changes in upright own-race and other-race faces. Standard error bars are shown. 
upright performance was well above chance for at least three of the four morph difference levels. There were no other significant effects.

We also conducted an ANCOVA, with upright accuracy as the covariate, to determine whether the larger inversion decrement for configural than for component changes was due solely to (upright) configural changes' being easier to detect. It was not. The effect of change type remained significant $[F(1,77)=8.24, p<.006]$, indicating that configural coding was more disrupted by inversion than was component coding, independent of difficulty level.

\section{DISCUSSION}

This study provides the first direct evidence for an ownrace advantage in configural coding, with better detection of experimentally manipulated configural changes in own-race than in other-race faces. The own-race advantage did not interact with race of participant, ruling out any account in terms of differences between the Caucasian and Chinese stimulus sets. It was a small effect in absolute terms (around 3.5\%). However, when considered as a proportion of the difference in performance between upright and inverted faces (around 11\%), which sets an upper bound on the difference between own- and otherrace faces, it is quite substantial.

A surprising result was that sensitivity to component changes was also greater in own-race than in other-race faces. Moreover, this own-race advantage was no smaller than the own-race advantage for detecting configural changes. We should be cautious about comparing the relative size of these two effects, because we have no metric for assessing whether component and configural changes were comparable (e.g., in terms of population $z$ scores), and they were not equally discriminable. Nevertheless, these results clearly show that face expertise is associated with superior coding of component, as well as configural, information.

An own-race advantage for component coding does not depend on the specific method of manipulating component information or the specific recognition test used here. When participants must use components to recognize previously studied faces in an old/new recognition paradigm because test faces are scrambled, an own-race advantage is also found (Hayward, Rhodes, \& Schwaninger, 2006).

In the introduction, we suggested that inversion decrements are difficult to interpret because inversion disrupts holistic and component, as well as configural, coding. Our results identify a further problem with their interpretation. Inversion decrements were also sensitive to task difficulty, independent of the type of coding. Furthermore, the inversion decrement for component changes could be substantial (e.g., 13\% for the easiest component changes). Therefore, unless upright performance is equated, differences in inversion decrements cannot be attributed to differences in configural processing. This condition was not met in previous studies that have inferred better configural coding of own-race faces from larger inversion decrements for own-race faces (Rhodes et al., 1989; Sangrigoli $\&$ de Schonen, 2004).

Expert face coding mechanisms have generally been investigated by comparing faces to other objects. This approach has identified configural and holistic coding as important computational mechanisms in face coding (for reviews, see Peterson \& Rhodes, 2003). A complementary approach, taken here, compares the processing of own-race faces and other-race faces, with which people have less expertise. Using this approach, we have shown

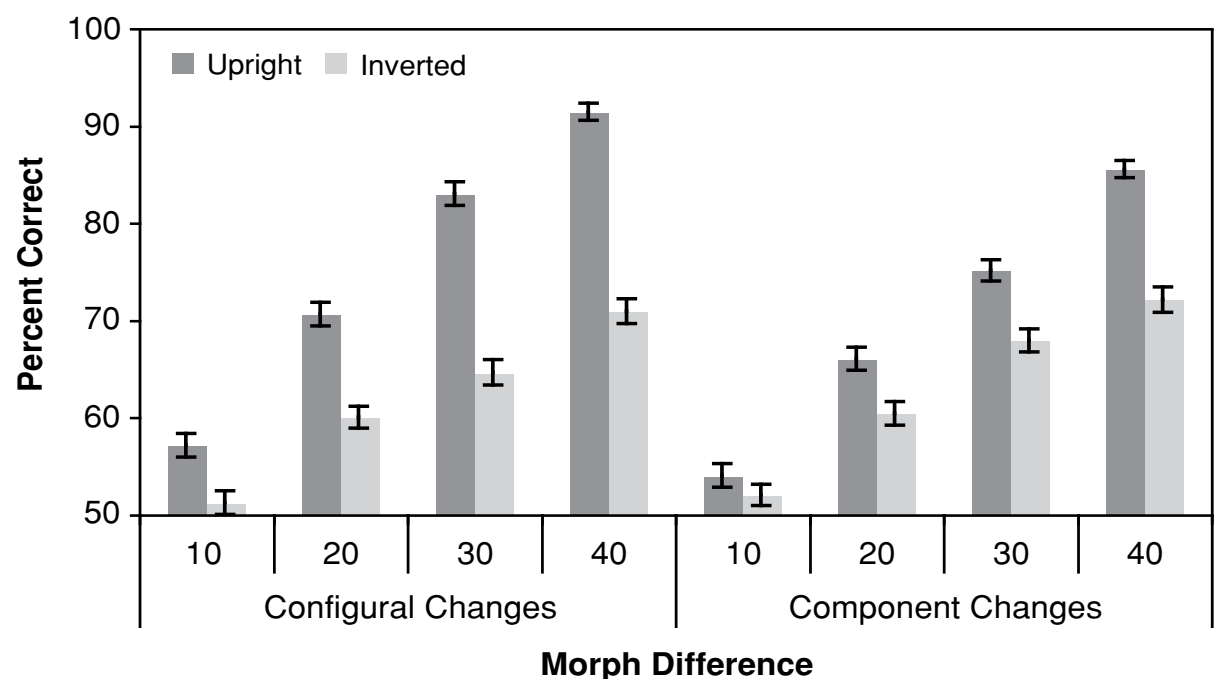

Figure 4. Percent correct for upright and inverted faces as a function of morph difference. Separate graphs are shown for configural and component changes. Standard error bars are shown. 
that face expertise facilitates configural coding. Others have shown that it facilitates holistic coding (at least for Caucasian participants; Michel et al., 2006; Tanaka et al., 2004). Taken together, these results suggest that faceselective computational mechanisms are engaged more effectively by classes of faces with which we have more experience. However, we also found an own-race advantage for component coding, which is not face selective (e.g., Maurer et al., 2002). Therefore, the effects of face expertise are not limited to face-selective coding mechanisms. It may be timely to go beyond the focus on configural and holistic processing that has dominated face perception research for the last decade, to consider how expertise affects other aspects of face processing.

\section{REFERENCES}

Bartlett, J. C., Searcy, J., \& Abdi, H. (2003). What are the routes to face recognition? In M. A. Peterson \& G. Rhodes (Eds.), Perception of faces, objects, and scenes: Analytic and holistic processing (pp. 2152). Oxford: Oxford University Press.

Bothwell, R. K., Brigham, J. C., \& Malpass, R. S. (1989). Crossracial identification. Personality \& Social Psychology Bulletin, 15, $19-25$.

Brigham, J. C., Maass, A., Snyder, L. D., \& Spaulding, K. (1982). Accuracy of eyewitness identifications in a field setting. Journal of Personality \& Social Psychology, 42, 673-681.

ByATt, G., \& RHodes, G. (2004). Identification of own-race and otherrace faces: Implications for the representation of race in face space. Psychonomic Bulletin \& Review, 11, 735-741.

Cabeza, R., \& Kato, T. (2000). Features are also important: Contributions of featural and configural processing to face recognition. Psychological Science, 11, 429-433.

Caldara, R., Thut, G., Servoir, P., Michel, C. M., Bovet, P., \& Renault, B. (2003). Face versus non-face object perception and the 'other-race' effect: A spatio-temporal event-related potential study. Clinical Neurophysiology, 114, 515-528.

CAReY, S. (1992). Becoming a face expert. In V. Bruce, A. Cowey, A. W. Ellis, \& D. I. Perrett (Eds.), Processing the facial image (pp. 95-102). Oxford: Oxford University Press, Clarendon Press.

Chiroro, P., \& Valentine, T. (1995). An investigation of the contact hypothesis of the own-race bias in face recognition. Quarterly Journal of Experimental Psychology, 48A, 879-894.

DEHON, H., \& BrÉDART, S. (2001). An "other-race" effect in age estimation from faces. Perception, 30, 1107-1113.

Diamond, R., \& CAREY, S. (1986). Why faces are and are not special: An effect of expertise. Journal of Experimental Psychology: General, 115, 107-117.

Farah, M. J., Tanaka, J. W., \& Drain, H. M. (1995). What causes the face inversion effect? Journal of Experimental Psychology: Human Perception \& Performance, 21, 628-634.

Farah, M. J., Wilson, K. D., Drain, H., \& Tanaka, J. (1998). What is "special" about face perception? Psychological Review, 105, 482498.

Freire, A., Lee, K., \& Symons, L. A. (2000). The face-inversion effect as a deficit in the encoding of configural information: Direct evidence. Perception, 29, 159-170.

Furl, N., Phillips, P. J., \& O'Toole, A. J. (2002). Face recognition algorithms and the other-race effect: Computational mechanisms for a developmental contact hypothesis. Cognitive Science, 26, 797-815.

Golby, A. J., Gabrieli, J. D. E., Chiao, J. Y., \& Eberhardt, J. L. (2001). Differential responses in the fusiform region to same-race and other-race faces. Nature Neuroscience, 4, 845-850.

Goldstone, R. L. (2003). Do we all look alike to computers? Trends in Cognitive Sciences, 7, 55-57.

Haxby, J. V., Hoffman, E. A., \& Gobbini, M. I. (2000). The distributed human neural system for face perception. Trends in Cognitive Sciences, 4, 223-233.

Hayward, W. G., Rhodes, G., Schwaninger, A. (2006). An own-race advantage for components as well as configurations in face recognition. Manuscript submitted for publication.

Humphreys, G. W., Hodsoll, J., \& Campbell, C. (2005). Attending but not seeing: The "other-race" effect in face and person perception studied through change blindness. Visual Cognition, 12, 249-262.

Kanwisher, N. (2000). Domain specificity in face perception. Nature Neuroscience, 3, 759-763.

LEDER, H., \& BRUCE, V. (2000). When inverted faces are recognized: The role of configural information in face recognition. Quarterly Journal of Experimental Psychology, 53A, 513-536.

Maurer, D., Le Grand, R., \& Mondloch, C. J. (2002). The many faces of configural processing. Trends in Cognitive Sciences, 6, 255260.

McKone, E., \& PeH, Y. X. (2006). Memory conjunction errors for realistic faces are consistent with configural processing. Psychonomic Bulletin \& Review, 13, 106-111.

Meissner, C. A., \& Brigham, J. C. (2001). Thirty years of investigating the own-race bias in memory for faces. Psychology, Public Policy \& Law, 7, 3-35.

Michel, C., Caldara, R., \& Rossion, B. (2006). Same-race faces are perceived more holistically than other-race faces. Visual Cognition, 14, 55-73.

Mondloch, C. J., Le Grand, R., \& Maurer, D. (2002). Configural face processing develops more slowly than featural face processing. Perception, 31, 553-566.

Murray, J. E., Rhodes, G., \& Schuchinsky, M. (2003). When is a face not a face? The effects of misorientation on mechanisms of face perception. In M. A. Peterson \& G. Rhodes (Eds.), Perception of faces, objects, and scenes: Analytic and holistic processing (pp. 75-91). Oxford: Oxford University Press.

O'Toole, A., Peterson, J., \& Deffenbacher, K. A. (1996). An “otherrace effect" for categorizing faces by sex. Perception, 25, 669-676.

Peterson, M. A., \& Rhodes, G. (2003). Perception of faces, objects, and scenes: Analytic and holistic processing. Oxford: Oxford University Press.

Platz, S. J., \& Hosch, H. M. (1988). Cross-racial/ethnic eyewitness identification: A field study. Journal of Applied Social Psychology, 18, 972-984.

Rhodes, G., Tan, S., Brake, S., \& Taylor, K. (1989). Expertise and configural coding in face recognition. British Journal of Psychology, 80, 313-331.

Rossion, B., \& GAUTHIER, I. (2002). How does the brain process upright and inverted faces? Behavioral \& Cognitive Neuroscience Reviews, 1, 62-74

SANGRIGOLI, S., \& DE SCHONEn, S. (2004). Effect of visual experience on face processing: A developmental study of inversion and nonnative effects. Developmental Science, 7, 74-87.

TANAKa, J. W., \& Farah, M. J. (1993). Parts and wholes in face recognition. Quarterly Journal of Experimental Psychology, 46A, 225-245.

TANaKa, J. W., \& FARAH, M. J. (2003). The holistic representation of faces. In M. A. Peterson \& G. Rhodes (Eds.), Perception of faces, objects, and scenes: Analytic and holistic processing (pp. 53-74). Oxford: Oxford University Press.

TAnaKa, J. W., Kiefer, M., \& BuKaCh, C. M. (2004). A holistic account of the own-race effect in face recognition: Evidence from a crosscultural study. Cognition, 93, B1-B9.

VAlentine, T., \& BRUCE, V. (1986). The effect of race, inversion and encoding activity upon face recognition. Acta Psychologica, 61, 259273.

Walker, P. M., \& Tanaka, J. W. (2003). An encoding advantage for own-race versus other-race faces. Perception, 32, 1117-1125.

\section{NOTES}

1. The specialization may not be complete, in that these mechanisms may also be used for other homogeneous classes with which people have expertise (e.g., Diamond \& Carey, 1986). 
2. The basic arrangement of eyes above nose above mouth, shared by all faces, is a first-order configuration. Second-order relations are variations within this first-order configuration, which are used to distinguish one face from another (Diamond \& Carey, 1986). Configural coding normally refers to coding of these second-order relations, although it has also been used to refer collectively to first-order relational, second-order relational, and holistic coding (Maurer, Le Grand, \& Mondloch, 2002).

3. Comparable results were obtained using absolute decrement scores (upright - inverted).
4. There was no speed-accuracy trade-off. Unsurprisingly, reaction times increased with difficulty (decreasing morph level) $[F(3,234)=$ $71.47, p<.0001]$. Morph level interacted with face race, and with face race and participant race (both $F \mathrm{~s}<3.51$ ), with a slightly bigger effect of morph level for own-race than for other-race faces, particularly for Chinese participants. These interactions have no theoretical significance.

(Manuscript received June 27, 2005;

revision accepted for publication October 6,2005 .) 